\title{
GERMINAÇÃO IN VITRO E EX VITRO DE Inga vera Willd. subsp. affinis (DC.) T.D. Penn. ${ }^{1}$
}

\author{
Germination in vitro and ex vitro of Inga vera Willd. subsp. affinis (DC.) T.D. Penn.
}

\author{
Vanessa Cristina Stein ${ }^{2}$, Renato Paiva ${ }^{3}$, Fernanda Pereira Soares ${ }^{4}$, Rairys Cravo Nogueira ${ }^{5}$, \\ Luciano Coutinho Silva ${ }^{6}$, Eduardo Emrich ${ }^{7}$
}

\begin{abstract}
RESUMO
O Inga vera Will subsp. affinis (DC). T.D. Penn. é uma espécie frutífera nativa do Cerrado, importante na recuperação de matas ciliares degradadas. Entretanto, apresenta sua propagação dificultada pelo fato de suas sementes serem recalcitrantes, ou seja, não tolerarem a perda de água. O objetivo deste trabalho foi estudar aspectos da germinação ex vitro e in vitro de ingazeiro. Para tanto, foram avaliados os efeitos de diferentes substratos: areia, Plantmax ${ }^{\circledR}$ e Areia+ Plantmax ${ }^{\circledR}$; diferentes concentrações de sais: WPM, $\mathrm{WPM} / 2$, MS e MS/2, e diferentes concentrações de $\mathrm{GA}_{3}(0,5,10,17$ e $20 \mu \mathrm{M})$ no meio de cultura. Observou-se que, na germinação ex vitro, o substrato Plantmax ${ }^{\circledR}$ proporcionou maior porcentagem de germinação (82\%). Com relação à germinação in vitro, a maior percentagem de germinação foi obtida utilizando-se meio de cultura WPM/2 $(96 \%)$. A adição de GA no meio de cultura não foi estatisticamente significativa, no entanto, a concentração de $20 \mu \mathrm{M}$ de GA 3 proporcionou um aumento na germinabilidade de sementes de ingazeiro.
\end{abstract}

Termos para indexação: Espécies frutíferas, substratos, meios de cultura, GA,

\section{ABSTRACT}

The Inga vera Will subsp. affinis (DC). T.D. Penn. is fruit native specie from cerrado, commonly for recovering devastated areas. However, its propagation is complicated due to the fact that the seeds are recalcitrant and does not support water loss. The objective of this work was to study Inga vera Willd. subsp. affinis (DC.) T.D. Penn. ex vitro and in vitro germination aspects. For this purpose, different substrates: sand, Plantmax ${ }^{\circledR}$ and sand+ Plantmax ${ }^{\circledR}$; different salt concentrations: WPM, WPM/2, MS and MS/ 2 , and different $\mathrm{GA}_{3}$ concentrations $(0,5,10,17$ and $20 \mu \mathrm{M})$ were evaluated. The results showed that, in the ex vitro germination, the use of Plantmax ${ }^{\circledR}$ provided the highest germination percentage (82\%). Regarding the in vitro germination, highest percentage was observed using WPM/2 (96\%). The addition of $\mathrm{GA}_{3}$ was not statistically significant although the concentration of $20 \mu \mathrm{M}$ promoted an increase in the germination of Inga vera seeds.

Index terms: Fruity trees, micropropagation, BAP, NAA.

\section{(Recebido em 5 de setembro de 2006 e aprovado em 8 de dezembro de 2006)}

\section{INTRODUÇÃO}

O Inga vera Will subsp. affinis (DC). T.D. Penn. é uma espécie frutífera nativa do Cerrado, importante na recuperação de matas ciliares degradadas. No entanto, apresenta sua propagação dificultada pelo fato de suas sementes serem recalcitrantes, ou seja, não tolerarem a perda de água.

Segundo Mûniz-Meléndez (1978), as sementes de ingazeiro são vivíparas, a radícula começa seu crescimento antes da abertura do fruto, quando esse ainda está ligado à planta-mãe e, ao cair sobre o solo, o fruto se decompõe e as sementes continuam seus processos germinativos. A viviparidade pode estar relacionada com o elevado teor de água após a maturação das sementes e/ou com a baixa concentração de substâncias inibidoras presentes no fruto e ou na própria semente (CHIN et al., 1989).

$\mathrm{O}$ ingazeiro floresce durante os meses de agosto e novembro e a maturação dos frutos se dá de dezembro a fevereiro (LORENZI, 2000). Assim, a curta longevidade das

${ }^{1}$ Parte da Dissertação de Mestrado da primeira autora

2Bióloga, Doutoranda em Agronomia/Fisiologia Vegetal - Departamento de Biologia/DBI - Universidade Federal de Lavras/UFLA - Cx. P. 3037 - $37200-000$ Lavras, MG - vanessastein@oi.com.br

${ }^{3}$ Engenheiro Agrônomo, Ph.D. em Agronomia, Professor Adjunto - Departamento de Biologia/DBI - Universidade Federal de Lavras/UFLA - Cx. P. 3037 37200-000 - Lavras, MG - renpaiva@ufla.br

${ }^{4}$ Engenheira Agrônoma, Doutoranda em Agronomia/Fisiologia Vegetal - Departamento de Biologia/DBI - Universidade Federal de Lavras/UFLA - Cx. P. 3037 37200-000 - Lavras, MG - fernandapsoares@hotmail.com

${ }^{5}$ Bióloga, Pós-Doutoranda em Agronomia/Fisiologia Vegetal - Departamento de Biologia/DBI - Universidade Federal de Lavras/UFLA - Cx. P. 3037 37200-000 - Lavras, MG - rairys@yahoo.com.br

${ }^{6}$ Graduando em Agronomia - Departamento de Biologia/DBI - Universidade Federal de Lavras/UFLA - Cx. P. 3037 - $37200-000$ - Lavras, MG Bolsista Iniciação Científica - lucoutsilva@yahoo.com.br

'Engenheiro Agrônomo - Departamento de Biologia/DBI - Universidade Federal de Lavras/UFLA - Cx. P. 3037 - $37200-000$ - Lavras, MG bucsan_emrich@yahoo.com.br 
sementes de ingazeiro restringe sua utilização, pois a semeadura deve ser realizada logo após a extração dos frutos (STUBSGAARD, 1990). Conseqüentemente, inviabiliza-se a instalação de viveiros sob condições climáticas favoráveis à germinação e ao desenvolvimento das mudas, causando desuniformidade na produção e, além disso, limita a oferta de mudas em determinadas épocas do ano ou, ainda, torna-as disponíveis em épocas inadequadas ao plantio. A ocorrência de adversidades ambientais entre a formação e a colheita dos frutos, tais como geadas, estiagens e problemas fitossanitários, pode provocar a diminuição na oferta de mudas, em virtude das dificuldades de manutenção de estoques de sementes (FONSECA \& FREIRE, 2003).

Pela impossibilidade de formação de mudas em épocas distintas das que são produzidas as sementes em seu habitat, também fica inviabilizada a sua inclusão nos programas voltados à recuperação de áreas nativas degradadas (BARBEDO, 1997). Neste contexto, a multiplicação assexual é a melhor opção para superar os problemas com a propagação por meio de sementes (HARTMANN \& KESTER, 1976).

A conservação in vitro, seja em condições de crescimento lento ou criopreservação de eixos embrionários isolados, ou de suas partes, é o método mais promissor para a conservação a médio e longo prazo, respectivamente (FAIAD et al., 1998). Desse modo, Gomes (2003) afirma que condições ambientais apropriadas para o processo de germinação podem ser fornecidas em laboratórios por meio da multiplicação in vitro.

Assim, estudos de meios de cultura que favoreçam a germinação in vitro de espécies recalcitrantes são importantes, tanto para maximizar a taxa de germinação como para obter plântulas uniformes com qualidade genética e fitossanitária adequada.

O suprimento adequado em água, composição de gases e temperatura convenientes, assim como a luz, são requisitos fundamentais para a germinação. Por outro lado, Mayer \& Poljakoff-Mayber (1989) afirmam que fatores como composição química e balanço hormonal influenciam no processo germinativo. Melo et al. (1979) apontam que o tratamento de sementes com giberelinas pode promover a germinação.

$\mathrm{O}$ efeito de giberelinas como regulador de crescimento desencadeador do processo de germinação vem sendo comprovado em diversas espécies. Sua atuação como indutor da transcrição de diversas hidrolases permite a mobilização de reservas a serem utilizadas pelo embrião (TAIZ \& ZEIGER, 2004). Sendo assim, sementes que possuem uma concentração relativa de giberelina baixa, quando tratadas com ácido giberélico $\left(\mathrm{GA}_{3}\right)$ na concentração adequada, teriam uma germinação mais homogênea e em maior quantidade. Segundo Kochaba et al. (1974), a presença de ácido giberélico no meio de cultura proporciona a iniciação de uma zona meristemática radicular ou estimula o desenvolvimento de uma zona radicular existente.

A presença de uma concentração maior ou menor de sais, ou outros compostos osmoticamente ativos, no meio de germinação, de acordo com a espécie e com o potencial osmótico de suas sementes, poderá ser o fator responsável pela adequada hidratação destas. Consequientemente, poderá viabilizar ou inviabilizar a ocorrência do processo germinativo, a partir de uma embebição adequada ou não (DODD \& DONOVAN, 1999).

Portanto, o objetivo deste trabalho foi estudar aspectos da germinação in vitro e ex vitro de Inga vera Will subsp. affinis (DC). T.D. Penn.

\section{MATERIAL E MÉTODOS}

\section{Material vegetal}

Frutos maduros de ingazeiro foram coletados de populações naturais da localidade denominada cachoeira

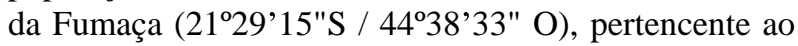
município de Carrancas, MG.

\section{Germinação ex vitro}

\section{Efeito de diferentes substratos}

Após a retirada manual do tegumento, as sementes foram acondicionadas em gerbox, contendo três diferentes tipos de substratos: areia, Plantmax ${ }^{\circledR}$ e areia + Plantmax ${ }^{\circledR}$ na proporção de 1:1 (v/v). Cada tratamento constou de cinco repetições, com dez sementes, mantidas em germinador tipo BOD (sigla em inglês para demanda bioquímica de oxigênio) à temperatura de $25^{\circ} \mathrm{C}$ e fotoperíodo 16 horas. Em intervalos de dois dias, foram acrescentados $5 \mathrm{~mL}$ de água por gerbox.

A emergência foi avaliada aos sete e quatorze dias (BARBEDO \& CÍCERO, 1998), após a semeadura, sendo considerada germinada quando houve a emergência do epicótilo. Aos quatorze dias, foram avaliados o número médio de folhas e a altura média da plântulas.

O delineamento estatístico utilizado foi o inteiramente casualizado e os resultados foram submetidos à análise de variância, utilizando-se o Software Statistical Analisys System $\left(\mathrm{SAS}^{\circledR}\right)$. As médias foram comparadas pelo teste de Tukey, a 5\% de probabilidade. 


\section{Germinação in vitro}

\section{Efeito de diferentes meios de cultura}

Os frutos foram lavados em água corrente por 20 minutos e transferidos para câmara de fluxo laminar, no qual foram imersos em álcool $70 \%$ (v/v) por 60 segundos e em solução de hipoclorito de sódio $(\mathrm{NaOCl})$ com $1 \%$ de cloro ativo por 20 minutos. Posteriormente, foram lavados em água destilada e autoclavada e abertos por corte longitudinal, isolando-se as sementes, que foram inoculadas em diferentes meios de cultura.

Foram testados os meios de cultura WPM (LLOYD \& MCCOWN, 1980), WPM/2, MS (MURASHIGE \& SKOOG, 1962) e MS/2, suplementados com $3 \%$ de sacarose e solidificados com ágar $0,7 \%$. $\mathrm{O} \mathrm{pH}$ foi corrigido para 5,8 antes da autoclavagem a $120^{\circ} \mathrm{C}$, durante 20 minutos.

Após a inoculação, as sementes foram mantidas em sala de crescimento sob irradiância de fótons de 36 $\mathrm{mmol} \mathrm{m} \mathrm{m}^{-2} \mathrm{~s}^{-1}$, fotoperíodo de 16 horas e temperatura de $25 \pm 2^{\circ} \mathrm{C}$. A avaliação foi realizada aos sete e quatorze dias de incubação (BARBEDO \& CÍCERO, 1998), sendo observada a porcentagem de sementes germinadas em cada tratamento. Foi considerada germinada a semente que apresentava a radícula protrundida.

O delineamento estatístico utilizado foi o inteiramente casualizado, com 8 repetições por tratamento, cada uma composta por um frasco com 3 sementes. Os resultados foram submetidos à análise de variância $\left(\mathrm{SAS}^{\circledR}\right)$, sendo as médias comparadas pelos Modelos Lineares não Generalizados.

\section{Efeito do $\mathrm{GA}_{3}$}

O processo de assepsia das sementes foi idêntico ao descrito anteriormente. Foram testados três níveis de $\mathrm{GA}_{3}(0,5,10,17$ e $20 \mu \mathrm{M})$ no meio de cultura MS suplementado com $3 \%$ de sacarose e solidificado com ágar $0,7 \%$. O pH foi corrigido para 5,8 antes da autoclavagem.

Após a inoculação, as sementes foram mantidas em sala de crescimento sob irradiância de fótons de 36 mmol m $\mathrm{m}^{-2} \mathrm{~s}^{-1}$, fotoperíodo de 16 horas e temperatura de $25 \pm 2^{\circ} \mathrm{C}$. A avaliação foi realizada aos sete e quatorze dias de incubação (BARBEDO \& CÍCERO, 1998), sendo observada a porcentagem de sementes germinadas em cada tratamento. Foi considerada germinada a semente que apresentava a radícula protrundida.

Foram utilizadas 10 repetições por tratamento, sendo cada uma composta por um tubo de ensaio e cada tubo contendo uma semente.

O delineamento estatístico utilizado foi o inteiramente casualizado, sendo as médias dos tratamentos comparadas pelo Teste de Tukey, com significância fixada em $5 \%$.

\section{RESULTADOS E DISCUSSÃO}

\section{Germinação ex vitro}

Houve diferenças estatisticas, entre as porcentagens de sementes de ingazeiro germinadas nos substratos areia, areia + Plantmax ${ }^{\circledR}$ e Plantmax ${ }^{\circledR}$. Os maiores percentuais de emergência aos sete e aos quatorze dias foram obtidos no substrato Plantmax ${ }^{\circledR}$ com $50 \%$ e $82 \%$ respectivamente, sendo esse bem superior ao substrato areia $(26 \%$ e $58 \%)$ e ao substrato areia + Plantmax ${ }^{\circledR}(34 \%$ e $66 \%$ ) (Figura 1). Segundo Smiderle (2001), o Plantmax ${ }^{\circledR}$, possui composição química bem balanceada, contendo, principalmente, os nutrientes $\mathrm{N}, \mathrm{P}, \mathrm{K}, \mathrm{Ca}$ e $\mathrm{Mg}$.

Os resultados encontrados para a germinação, corroboram aqueles obtidos por Barbedo \& Cicero (1998), que obtiveram $83 \%$ de germinação em substrato de papel, para a espécie Inga uruguensis Hook. \& Arn., porém divergem de Varela et al. (2005), que obtiveram menor germinabilidade em sementes de Acosmium nitens (Vog.) Yakolev (Leguminosae) no substrato areia, comparado ao substrato vermiculita.

Portanto, quanto aos substratos, deve-se considerar que a capacidade de retenção de água de cada um deles, aliada às características intrínsecas que regulam o fluxo de água para as sementes, pode influenciar os resultados (CASTRO et al., 2002).

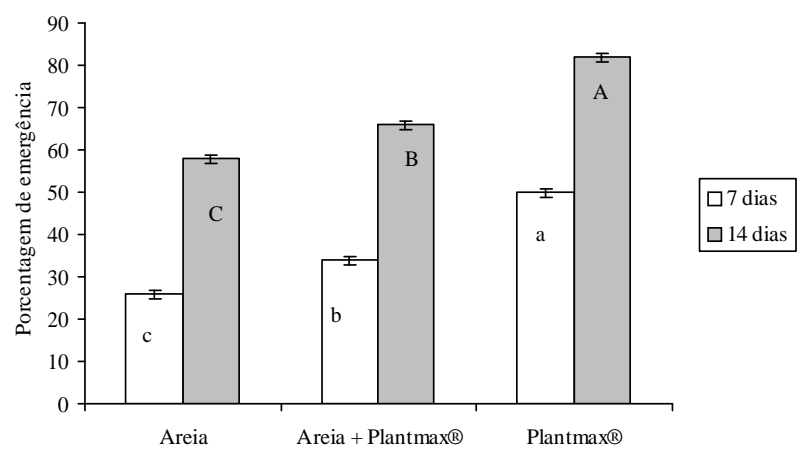

Figura 1 - Evolução da emergência de sementes de ingazeiro em diferentes substratos. UFLA, Lavras, MG, 2006.

Para as variáveis, tamanho da parte aérea e número de folhas em plântulas germinadas nos diferentes substratos, as plântulas germinadas em areia apresentam valores superiores, no entanto não diferem estatisticamente do Plantmax ${ }^{\circledR}$ (Tabela. 1). 
O substrato propicia ancoragem às plantas, de modo que elas se sustentem e, ao mesmo tempo, regula o suprimento de água e ar para as raízes, possibilitando bom desenvolvimento das culturas (MINAMI \& PUCHALA, 2000; TAVEIRA, 1996).

O Inga vera Willd. subsp. affinis (DC.) T.D. Penn. é uma espécie extremamente abundante nas áreas sazonalmente inundadas, das margens dos rios, por apresentar algumas adaptações anatômicas e morfológicas que a fazem suportar submersão do sistema radicular (SOARES, 2003).

\section{Germinação in vitro}

\section{Efeito de diferentes meios de cultura}

Pela análise de razão de chances (Tabela 2), verificou-se que o meio WPM/2 é o mais apropriado para a germinação de sementes de ingazeiro in vitro, tendo apresentado índice de $96 \%$, sendo superior ao WPM (66\%), MS/2 (75\%) e MS (30\%).

O meio nutritivo WPM apresenta $25 \%$ das concentrações de íons nitrato e amônia do meio MS (PASQUAL, 2001) e, segundo Premecz et al. (1978), elevadas pressões osmóticas reduzem o crescimento e afetam o metabolismo celular. Portanto, a diminuição do potencial osmótico promovido pela redução das concentrações de macro e micronutrientes do meio WPM/ 2 proporciona as maiores taxas de germinação.

No entanto, segundo Dodd \& Donovan (1999), a presença de uma concentração maior ou menor de sais, ou outros compostos osmoticamente ativos, no meio de germinação, de acordo com a espécie e com o potencial osmótico de suas sementes, poderá ser o fator responsável pela adequada hidratação destas. Conseqüentemente, poderá viabilizar ou inviabilizar a ocorrência do processo germinativo, a partir de uma embebição adequada ou não.

Emershad \& Ramming (1994) relataram altas porcentagens de germinação de embriões de nectarina (Prunus persica var. nucipersica Schneid) e pêssego (Prunus persica (L.) Batsch), cultivados em meio básico WPM, os quais atingiram $98 \%$ e $100 \%$ de germinação. Assim como, Soares (2005), que obteve uma maior porcentagem de germinação de sementes de mangabeira em meio nutritivo MS/2 e para murici, os meios de cultura mais eficientes para a germinação de sementes e embriões são o MS e WPM/2, sem sacarose (NOGUEIRA et al., 2004).

Foi verificado também que a taxa de germinação no meio WPM/2 (96\%) foi bem superior ao substrato Plantmax ${ }^{\circledR}(82 \%)$. Estudos sobre germinação in vitro de Pothomorphe umbellata L. Miq (VIANA et al., 1999) e de Norantea brasiliensis Choisy (CAMPOS, 2003) também mostraram maior germinação quando comparadas às cultivadas in vivo.

No entanto, apesar da superioridade de germinação no meio WPM/2, foi observada uma alta taxa de contaminação das sementes após a germinação (Tabela 3), pois este meio de cultura apresenta menor concentração de sais, portanto mais disponibilidade de água, proporcionando uma maior proliferação de bactérias e fungos endógenos (Figura 2).

Tabela 1 - Tamanho da parte aérea e número de folhas de ingazeiro em diferentes substratos. UFLA, Lavras, 2006.

\begin{tabular}{lcl}
\hline \multicolumn{1}{c}{ Tratamento } & Tamanho da parte aérea $(\mathrm{cm})$ & $\mathrm{N}^{\circ}$ de folhas \\
\hline Areia & $1,76 \mathrm{a}$ & $0,80 \mathrm{a}$ \\
Plantmax $^{\circledR}$ & $1,38 \mathrm{ab}$ & $0,24 \mathrm{ab}$ \\
Areia + Plantmax $^{\circledR}$ & $0,72 \mathrm{~b}$ & $0,12 \mathrm{~b}$ \\
\hline
\end{tabular}

Médias seguidas de letras distintas diferem entre si, pelo teste de Tukey, a $1 \%$ de probabilidade.

Tabela 2 - Análise da "Deviance" para o efeito do meio nutritivo na germinação de sementes de ingazeiro. UFLA, Lavras, MG, 2006.

\begin{tabular}{cccccc}
\hline Parâmetro & GL & Estimativa & Erro padrão & p-valor & Razão de chances \\
\hline Intercepto & 1 & 1,05 & 0,20 & 0,0001 & 0,875 \\
MS & 1 & $-1,18$ & 0,43 & 0,0059 & 2,250 \\
MS/2 & 1 & $-0,24$ & 0,31 & 0,4360 & 2,000 \\
WPM & 1 & $-0,36$ & 0,32 & 0,2649 & 2,887 \\
WPM/2 & 0 & 0,00 & 0,00 & & \\
\hline
\end{tabular}


Tabela 3 - Análise da "Deviance" para contaminação na germinação de sementes de ingazeiro. UFLA, Lavras, MG, 2006.

\begin{tabular}{cccccc}
\hline Parâmetro & GL & Estimativa & Erro padrão & p-valor & Razão de chances \\
\hline Intercepto & 1 & $-0,98$ & 0,57 & 2,88 & \\
MS & 1 & 1,38 & 0,64 & 4,61 & 0,08 \\
MS/2 & 1 & 1,38 & 0,66 & 4,61 & 0,03 \\
WPM & 1 & 1,09 & 0,66 & 2,71 & 0,03 \\
WPM/2 & 0 & 0,00 & 0,00 & & 0,09 \\
\hline
\end{tabular}
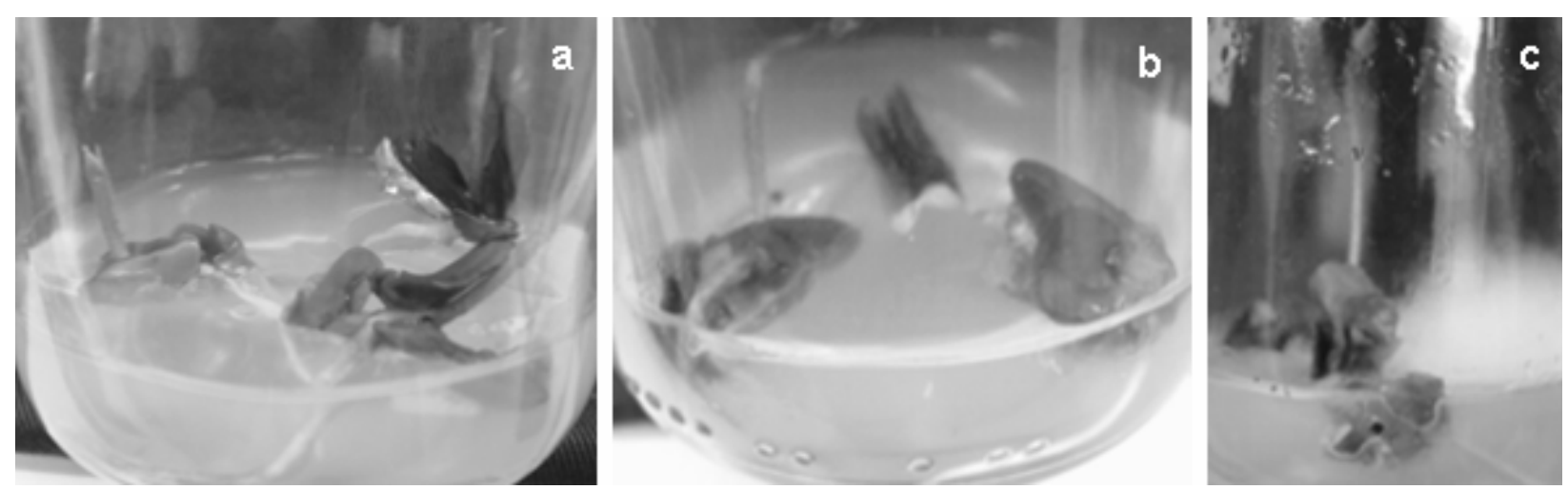

Figura 2 - Fotografias mostrando o aspecto visual da germinação in vitro de Ingá: WPM/2 (a); MS (b); contaminação (c). UFLA, Lavras, 2006. $\mathrm{Br}=1,5 \mathrm{~cm}(\mathrm{a}) ; 1 \mathrm{~cm}(\mathrm{~b}) ; 1 \mathrm{~cm}$ (c).

Franco \& Ferreira (2002) relata a grande incidência de fungos saprófitas nas sementes de Didymopanax morototoni (Aubl.) Decne. \& Planch. no meio MS. No entanto, o objetivo da germinação in vitro é a produção de explantes juvenis e assépticos para o estabelecimento de experimentos in vitro (COELHO et al., 2001).

\section{Efeito do $\mathrm{GA}_{3}$}

Não houve diferenças significativas entre as porcentagens de sementes de ingazeiro germinadas em diferentes concentrações de $\mathrm{GA}_{3}$

Apesar das diferenças entre os tratamentos não terem sido significativas, os maiores percentuais de germinação foram na concentração de $20 \mu \mathrm{M}$ de $\mathrm{GA}_{3}$ (Figura 3), com $100 \%$ de germinação.

As giberelinas desempenham uma importante função na germinação, na quebra de dormência e no controle da hidrólise das reservas (TAIZ \& ZIEGER, 2004), podendo provocar o amolecimento das camadas externas da semente, aumentando o suprimento de água e liberando os açúcares das paredes celulares (FRANCO \& FERREIRA, 2002). Elas atuam na expressão gênica, ativando a síntese de várias enzimas, dentre elas, enzimas que hidrolisam e mobilizam reservas dos tecidos (JELLER \& PEREZ, 2001).

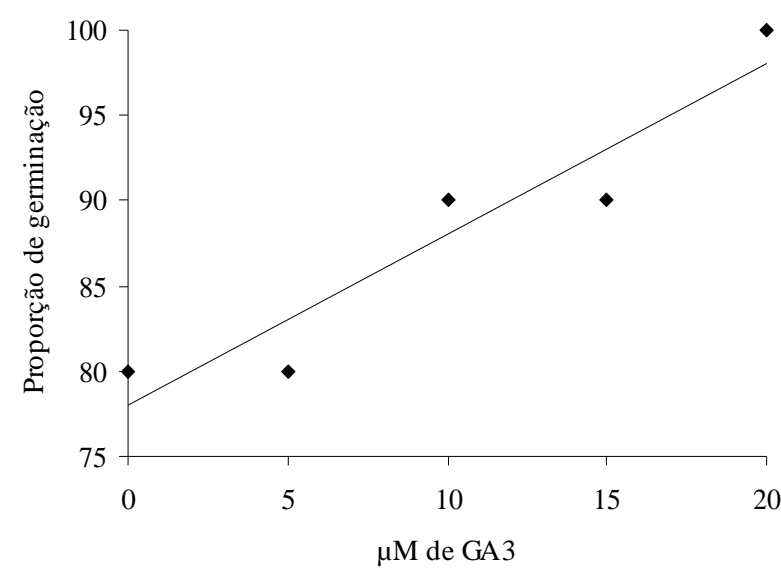

Figura 3 - Proporção de germinação de ingazeiro em diferentes concentrações de GA. UFLA, Lavras, MG, 2006.

Resultados descritos na literatura sobre o cultivo in vitro de mangabeira (Hancornia speciosa Gomes), mostram uma maior porcentagem de sementes germinadas 
(90\%) no meio de cultura WPM, suplementado com 1,5\% de sacarose e $0,75 \mu \mathrm{M}$ de $\mathrm{GA}_{3}$, diferenciando-se significativamente somente do tratamento controle, no qual estavam ausentes a sacarose e o ácido giberélico (SOARES, 2005).

\section{CONCLUSÃO}

O Plantmax ${ }^{\circledR}$ é o substrato mais adequado para a geminação ex vitro de ingazeiro

$\mathrm{O}$ substrato areia proporciona maior desenvolvimento de parte aérea e folhas em ingazeiro.

O WPM/2 é o meio de cultura indicado para a geminação in vitro de ingazeiro, no entanto, é necessário controle rígido da contaminação endógena.

Não é necessário a adição de $\mathrm{GA}_{3}$ na germinação in vitro de ingazeiro.

\section{REFERÊNCIAS BIBLIOGRÁFICAS}

BARBEDO, C. J. Armazenamento de sementes de Inga uruguensis Hook. \& Arn. 1997. 71 f. Tese (Doutorado) - Escola Superior de Agricultura Luiz de Queiroz, Piracicaba, 1997.

BARBEDO, C. J.; CICERO, S. M. Utilização do teste de condutividade elétrica para previsão do potencial germinativo de sementes de ingá. Scientia Agrícola, Piracicaba, v. 55, n. 2, p. 249-259, maio/ago. 1998.

CAMPOS, D. B. Métodos de propagação in vivo e in vitro de Norantea brasiliensis Choisy (Marcgraviaceae). 2003. 90 f. Monografia (Graduação) - Universidade do Estado do Rio de Janeiro, Rio de Janeiro, 2003.

CASTRO, I. M.; CORDEIRO, C.; LAMEIRA, O. A.; LOPES, S. da C.; RIOS, M. S. Germinação in vitro de Paricá (Schizolobium amazonicum Huber): obtenção de plântulas assépticas para iniciar a micropropagação. Biotecnologia Ciência \& Desenvolvimento, Brasília, v. 5, jul./ago. 2002.

CHIN, H. F.; HOR, Y. L.; LASSIM, M. B. Identification of recalcitrant seeds. Seed Science and Technology, Zurich, v. 12, n. 2, p. 429-436, 1989.

COELHO, M. C. F.; PINTO, J. E. B. P.; MORAIS, A. R.; CID, L. P. B.; LAMEIRA, O. A. Germinação de sementes de Sucupira-Branca [Pterodon pubescens (BENTH.) BENTH.] in vitro e ex vitro. Ciência e Agrotecnologia, Lavras, v. 25 , n. 1, p. 38-48, jan./fev. 2001.

DODD, G. L.; DONOVAN, L. A. Water potential and ionic effects on germination and seedling growth of two cold desert shrubs. American Journal of Botany, Columbus, v. 86, n. 8, p. 1146-1153, Aug. 1999.

EMERSHAD, R. L.; RAMMING, D. W. Effects of media on embryo enlargement, germination and plant development in early-ripening genotypes of Prunus grown in vitro. Plant Cell, Tissue and Organ Culture, Dordrecht, v. 37, n. 1, p. 55-59, Apr. 1994.

FAIAD, M. G. R.; SALOMÃO, A. N.; FERREIRA, F. R. P.; GONDIM, M. T. P.; WETZEL, M. M. V. S.; MENDES, R. A.; GOES, M. de. Manual de procedimentos para conservação de germoplasma semente em longo prazo na Embrapa. Brasília, DF: Embrapa, 1998. 21 p.

FONSECA, S. C. L.; FREIRE, H. B. Recalcitrants seeds: post-harvest problems. Bragantia, Campinas, v. 62, n. 2, p. 297-303, 2003.

FRANCO, E. T. H.; FERREIRA, A. G. Tratamentos prégerminativos em sementes de Didymopanax morototoni (Aubl.) Dcne. et Planch. Ciência Florestal, Santa Maria, v. 12, n. 1, p. 1-10, jun. 2002.

GOMES, G. A. C.; PAIVA, R.; PAIVA, P. D. de O.; SANTIAGO, É. J. A. de. Plant regeneration from callus culture of Maclura tinctoria, an endangered woody species. In vitro Cellular and Developmental Biology Plant, Wallingford, v. 39, n. 3, p. 293-295, May 2003.

HARTMAnn, H. T.; KESTER, D. E. Propagacion de plantas: princípios e práticas. México: México Continental, 1976. $810 \mathrm{p}$.

KOCHABA, J.; BUTTON, J.; SPIEGEL-ROY, P.; BORNMAN, C. H.; KOCHABA, M. Stimulation of rooting of citrus embryoids by gibberellic acid and adenine sulphate. Annals of Botany, New York, v. 38, n. 157, p. 795802, 1974.

JELLER, H.; PEREZ, S. C. J. G. de A. Efeitos dos estresses hidrico e salino e da ação de giberelina em sementes de Senna spectabili. Ciência Florestal, Santa Maria, v. 11, n. 1, p. 93-104, jun. 2001.

LLOYD, G.; McCOWN, B. Commercially-feasible micropropagation of Mountain laurel, Kalmia latifolia, by use of shoot tip culture. International Plant Propagation Society Proceedings, Washington, v. 30, p. 421-427, 1980. 
LORENZI, H. Árvores brasileiras: manual de identificação e cultivo de plantas arbóreas nativas do Brasil. 3. ed. Nova Odessa: Plantarum, 2000. v. 2.

MAYER, A. M.; POLJAKOFF-MAYBER, A. Germination stimulators and inhibitors: their effects and their possible regulatory role. In: . The germination of seeds. 4 . ed. Toronto: Pergamon, 1989. p. 174-178.

MELO, J. T.; RIBEIRO, J. F.; LIMA, V. L. G. F. Germinação de sementes de algumas espécies arbóreas nativas do Cerrado. Revista Brasileira de Sementes, Brasília, v. 1, n. 1, p. 8-12, 1979.

MINAMI, K.; PUCHALA, B. Produção de mudas de hortaliças de alta qualidade. Horticultura Brasileira, Brasília, v. 18, p. 162-163, jun. 2000. Suplemento.

MUÑIZ-MELÉNDEZ, E. Demographic analysis of the life history of Inga vera subs. vera. 1978. $48 \mathrm{f}$. Thesis (Master Science) - University of Tennessee, Knoxville, 1978.

MURASHIGE, T.; SKOOG, F. A revised medium for rapid growth and bioassays with tobacco tissue cultures. Physiologia Plantarum, Copenhagen, v. 15, n. 3, p. 473 497, 1962.

NOGUEIRA, R. C.; PAIVA, R.; CASTRO, A. H. de; VIEIRA, V. V.; ABBADE, L. C.; ALVARENGA, A. A. Germinação in vitro de murici-pequeno (Byrsonima intermedia A. Jusso. Ciência e Agrotecnologia, Lavras, v. 28, n. 5, p. 1053-1059, set./out. 2004.

PASQUAL, M. Textos acadêmicos: meios de cultura Lavras: FAEPE/UFLA, 2001. 127 p.

PREMECZ, G.; RUZICSKA, P.; OLAH, T.; FARKAS, G. L. Effect of 'osmotic stress' on protein and nucleic acid synthesis in isolated tobacco protoplasts. Planta, Berlin, v. 141, n. 2, p. 33-36, 1978.

SMIDERLE, O. J.; SALIBE, A. B.; HAYASHI, A. H.; MINAMI, K. Produção de mudas de alface, pepino e pimentão em substratos combinando areia, solo e plantmax $^{\circledR}$. Horticultura Brasileira, Brasília, v. 19, n. 3, p. 253-257, nov. 2001.

SOARES, F. P. Aspectos do cultivo in vitro da mangabeira (Hancornia speciosa Gomes). 2005. 137 p. Dissertação (Mestrado em Fisiologia Vegetal) - Universidade Federal de Lavras, Lavras, 2005.

SOARES, G. de A. Aspectos do cultivo in vitro do ingazeiro [Inga vera Willd. subsp. affinis (DC.) T. D. Penn.]. 2003. 107 p. Dissertação (Mestrado em Agronomia/Fisiologia Vegetal) - Universidade Federal de Lavras, Lavras, 2003.

STUBSGAARD, F. Seed moisture. Humlebaek: DFSC, 1990. $30 \mathrm{p}$.

TAIZ, L.; ZIEGER, E. Fisiologia vegetal. 3. ed. Porto Alegre: Artmed, 2004. 720 p.

TAVEIRA, J. A. M.Produção de mudas: substratos. Curitiba: SENAR, 1996. 88 p.

VARELA, V. P.; COSTA, S. de S.; RAMOS, M. B. P. Influência da temperatura e do substrato na germinação de sementes de itaubarana [Acosmium nitens (Vog.) Yakovlev] Leguminosae, Caesalpinoideae. Acta Amazônica, Manaus, v. 35, n. 1, p. 35-39, mar. 2005.

VIANA, V. R. C.; FIGUEIREDO, S. F. L.; ALBARELLO, N. Germinação in vitro de plantas medicinais I. Pothomorphe umbellata L. L. Miq. Revista Brasileira de Farmácia, Rio de Janeiro, v. 8, n. 1/2, p. 22-24, 1999. 